\title{
CASE NOTES
}

\section{ACUTE EYE LESIONS TREATED BY LAMELLAR CORNEAL GRAFTING*}

\author{
BY
}

\section{Louis Paufigue and Seymour Philps}

IT has now been abundantly demonstrated ${ }^{*}$ that, just as skin can be split and grafted, so also can layers of cornea be transferred from one eye to another and be made to grow. Moreover, if this procedure is carried out with due care, the graft will retain its transparency. Thus the optical indications for this course will need no emphasis; the reason for reporting the two ensuing cases is to emphasize that sometimes an optical and therapeutic action may be combined and that lamellar grafting is clearly

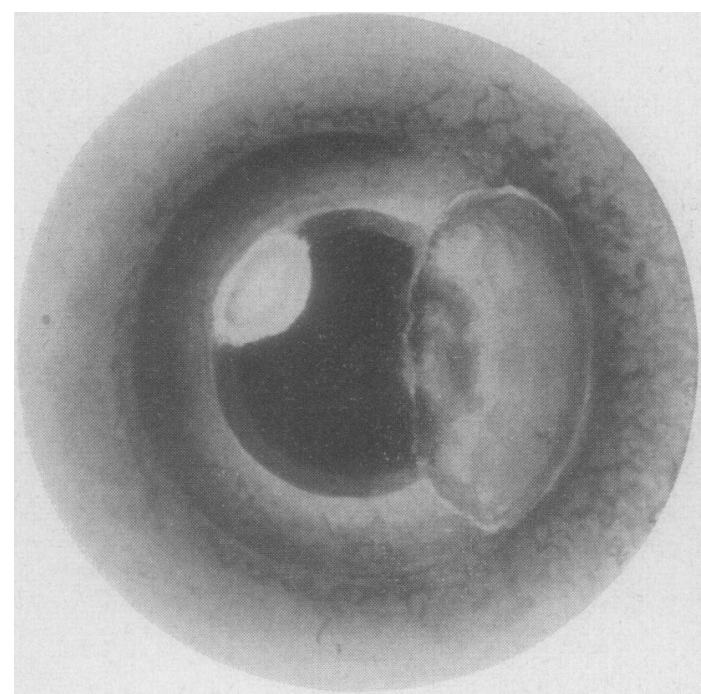

Fig. 1.-Case 1, right eye,

Februarv, 1950

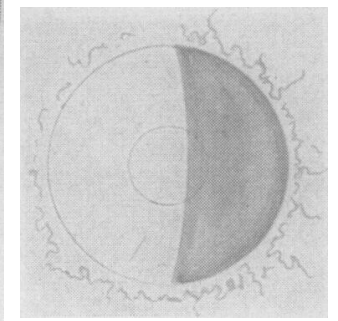

FIG. 2.-Case 1, area of corneal tissue removed.

indicated in several acute eye diseases. We think it no exaggeration to suggest that lamellar grafting saved the sight of the first patient and achieved a shorter convalescence and better optical result in the second than would have been possible by other means.

Case 1.-Mme. B., aged 45, was first seen in February, 1950, with a severe ulcer, involving more than a third of the right cornea. The ulcer was treated

- Received for publication October $23,1 \subseteq 50$ 
energetically with rest, heat, atropine, penicillin injections, etc., but continued to spread so that in a few days it had reached the pupil. A drawing made at that time shows the state of the eye (Fig. 1). It was then decided that, unless something were done, the sight of the eye and possibly the eye itself would be lost; accordingly excision of the ulcer and lamellar grafting of the cornea were carried out by one of us (L. P.) on February 26, 1950.

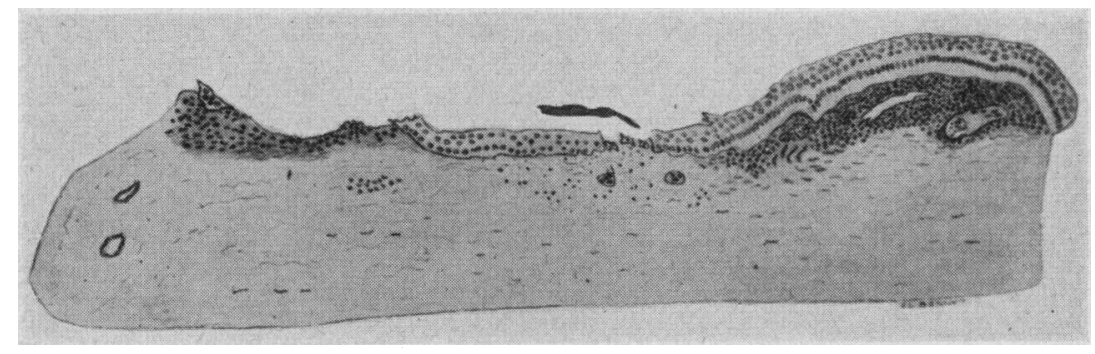

FIG. 3.-Case 1, microscopic appearance of corneal tissue removed.

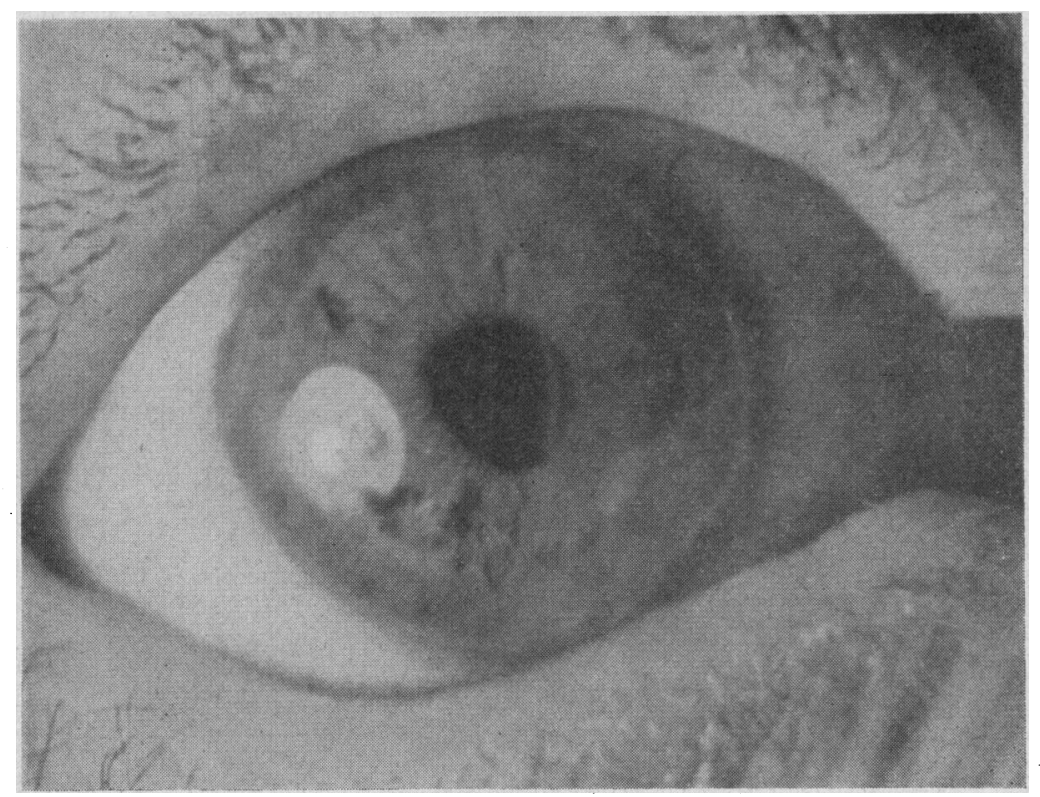

FIG. 4.- Case 1, right eye 4 weeks after operation. The grafted area is demarcated by a grey line crossing the pupil.

Operation.-A vertical incision was made through the corneal tissue from top to bottom of the cornea, and through $4 / 5$ of its thickness, this incision being then extended round the whole nasal limbus until the ulcerated area was enclosed by it (Fig. 2). The layer of cornea complete with ulcer was then dissected off (the microscopic appearance is shown in Fig. 3). The measurements of the excised area were then transferred to a donor eye and an exactly comparable 
graft cut and transferred to the host, the graft being retained in position by edge-to-edge sutures. These stitches were removed after four days, and ten days after the operation the eye was healed and quiet. Fig. 4 was taken four weeks after operation-vision $6 / 9$.

Case 2.-J. T., aged 48, a builder, suffered a severe lime-burn of the left cornea in March, 1950. The whole corneal surface was oedematous and stained with fluorescine, while a slough was present in the central corneal area. The cornea did not respond to ordinary measures and a tarsorrhaphy was performed two weeks after the injury, but the eye remained irritable and painful. The tarsorrhaphy was undone and the appearance of the eye $3 \frac{1}{2}$ weeks after the accident is shown in Fig. 5, when the tarsorrhaphy had just been undone, the cut area being visible on either lid.

Operation (S.P.).-The ulcerated area could now be enclosed within the circle of a $5.1 \mathrm{~mm}$. trephine, and a disk of tissue penetrating to $4 / 5$ of the corneal thickness was removed. This disk was replaced by a lamellar graft held in position by crossed corneal sutures and protected by a disk of egg membrane. Healing was uneventful; the sutures were removed in four days, and the appearance of the eye two weeks after operation is shown in Fig. 6. Pain and irritability had now gone, and the patient, being self-employed, actually returned to work three weeks after the operation. The final appearance, July, 1950, is shown in Fig. 7-vision 6/12.

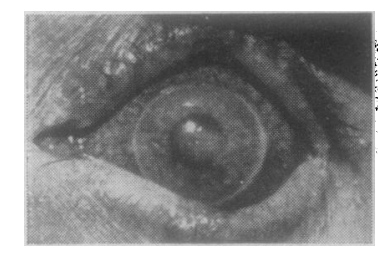

Fig. 5.-Case 2, left eye 3 weeks after being burnt by lime. Tarsorrhaphy has just been done.

Lamellar corneal grafting for acute eye disease is not new, but it seems that a wider application of this method would bring relief to some sufferers more quickly than older treatments.

\section{REFERENCE}

Paufigue, L., Sourdille, G. P., and Offret, G. (1948). " Les Greffes de la Cornée", published under the auspices of the Soc. franc. Ophtal. Masson, Paris, p. 139. 